\title{
Influence of the inter-jet spacing of diesel sprays on the combustion development
}

\author{
Raul Payri ${ }^{1}$, Jaime Gimeno ${ }^{1}$, Pedro Martí-Aldavarí ${ }^{1}$, Tomas Montiel ${ }^{* 1}$ \\ ${ }^{1}$ CMT - Motores Térmicos, Universitat Politècnica de València, Edificio 6D, 46022 Valencia, \\ Spain \\ *Corresponding author email: tomonpr@mot.upv.es
}

\begin{abstract}
In this work, the influence of the inter-jet spacing of diesel sprays on the lift-off length is analyzed. To this end, two multi-orifice diesel injectors with different outlet-holes distributions were employed. Specifically, the main injector allowed the study of the development of an isolated spray and a spray with neighbor jets during the same injection event. Moreover, the second injector had two additional orifices distribution, so a total of three inter-jet spacing configurations $\left(30^{\circ}-36^{\circ}-45^{\circ}\right)$ were compared to the performance of the isolated spray, maintaining the boundary conditions. First, momentum flux measurements were performed to compare the hydraulic behavior of the sprays, obtaining a high resemblance between them. Then, $\mathrm{OH}^{*}$ chemiluminescence measurements were done to capture the time-dependent lift-off length. The results showed that after certain proximity between sprays is reached, the lift-off length is considerably reduced as the interaction between sprays becomes a relevant factor. This behavior was attributed to a plausible increment of the entrained hot combustion products located along the periphery of the spray. Specifically, the entrained gas with higher temperature could induce autoignition around the nozzle region, causing a retraction of the lift-off length.
\end{abstract}

\section{Keywords}

inter-jet spacing, lift-off length, momentum flux, diesel injection.

\section{Introduction}

The legislation controlling the emissions of combustion engines has become increasingly restrictive over the years[1]. This phenomenon has motivated researchers across the world to find improvements regarding pollutant emissions and fuel economy continuously.

On this matter, an improvement has been found in injectors with multiple holes [2]. This configuration allows the use of smaller outlet-holes diameters, enhancing the mixing process and, consequently, the combustion efficiency [3].

However, as the number of holes increases, so does the proximity between the sprays coming out of the orifices. A trade-off appears between enhancing the air entrainment through smaller outlet diameters and droplet size, providing enough space of air between sprays, and avoiding jet-to-jet interaction.

Although some studies regarding the effect of inter-jet spacing on combustion have been made, its influence is not entirely defined[4]. Furthermore, most of the investigations were carried out in real diesel engines [5, 6]. These studies are essential for engine calibration, as the combustion process is carried out under real engine volume and boundary conditions, although these conditions are not entirely controlled or known.

However, the fundamental analysis through optically accessible test rigs allows the visualization of the combustion process in a simplified and nearly quiescent environment with controlled boundary conditions. Thus, high-fidelity experiments can be performed, focusing on specific parameters to better understand the topic of interest.

In this work, an optically accessible vessel is employed to simulate the boundary conditions found in the combustion chamber of compression ignition engines in terms of temperature, pressure, and oxygen concentration. Within the test rig, the combustion development is analyzed for various inter-jet spacing configurations. 
The following section will depict the equipment and techniques employed to obtain the measurements, followed by a description and discussion of the gathered results. Finally, the main conclusions of the work are summarized.

\section{Material and methods}

In the current section, the equipment and methodologies employed throughout the experiments are described.

\section{Diesel injectors}

The injectors used in this work are the latest iteration of the piezo common-rail type 5 from Continental. Both of them have an identical internal and external design, except for the distribution of the nozzle outlet orifices. These injectors were specifically manufactured to study the inter-jet spacing, and the geometrical configuration of each nozzle is depicted in Figure 1.

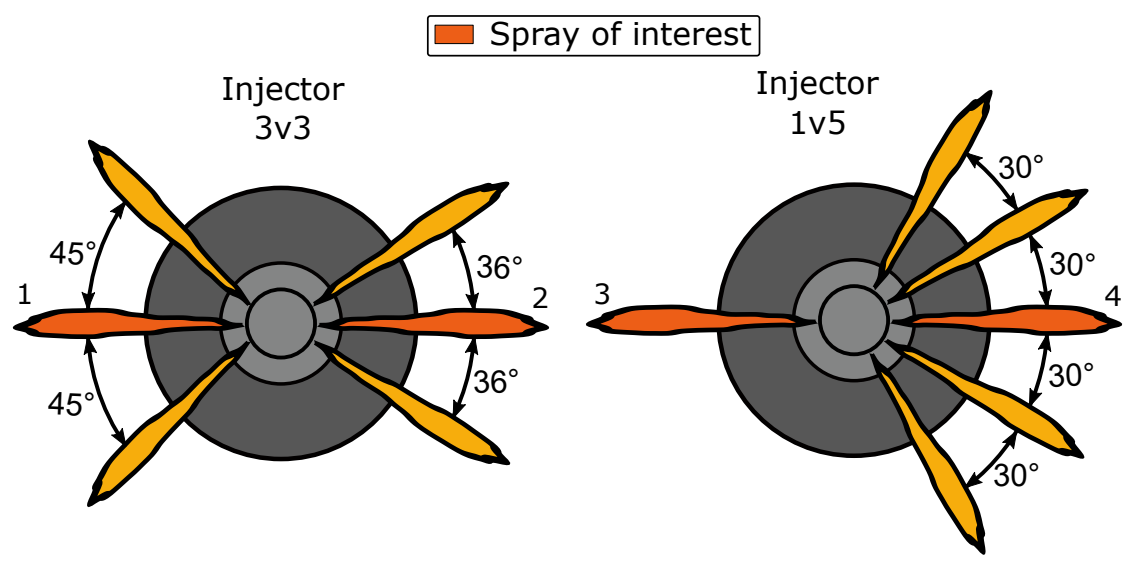

Figure 1. Outlet orifices configuration.

The injector $3 \mathrm{v} 3$ has three orifices on each side. One set of orifices has an inter-jet spacing of $45^{\circ}$ and the other of $36^{\circ}$, simulating an injector with 10 and 8 orifices, respectively. On the other hand, the injector $1 \mathrm{v} 5$ has five orifices on one side with a spacing between jets of $30^{\circ}$, representing an injector of 12 equally distributed holes. On the other side, the injector has one outlet orifice, which was used as the reference isolated spray as it has an inter-jet spacing of $120^{\circ}$ with its neighbor spray. Both injectors can manage up to $250 \mathrm{MPa}$ of injection pressure. In this work, the analyzed sprays were those located at the center of each configuration, ensuring the presence of neighbor jets. Lastly, the geometry of these orifices is presented in Table 1. The manufacturer provided the geometry of the injector.

Table 1. Geometry of the holes of interest.

\begin{tabular}{lcccc}
\hline Orifice & $\mathbf{1}$ & $\mathbf{2}$ & $\mathbf{3}$ & $\mathbf{4}$ \\
\hline Outlet diameter $[\mu \mathrm{m}]$ & 91.3 & 90.5 & 90.9 & 90.1 \\
Height angle [ $\left.{ }^{\circ}\right]$ & 74.7 & 74.8 & 74.7 & 74.8 \\
K-factor [-] & 5.1 & 5.2 & 5.0 & 5.1 \\
\hline
\end{tabular}

\section{Momentum Flux measurements}

Before the optical measurement of the combustion process, the hydraulic behavior of the injectors was analyzed in the Momentum Flux Test rig. With this equipment, it is possible to quantitatively assess the hydraulic response of each hole separately, obtaining various parameters such as momentum flux signal in time, the hydraulic delay after the start of energizing, and qualitative measurement of the injected mass [7]. To perform the experiment, the hole of interest is aligned to face a pressure sensor (Figure 2), which captures the impact force of the spray during the injection process. This test rig is described in detail in [8]. 


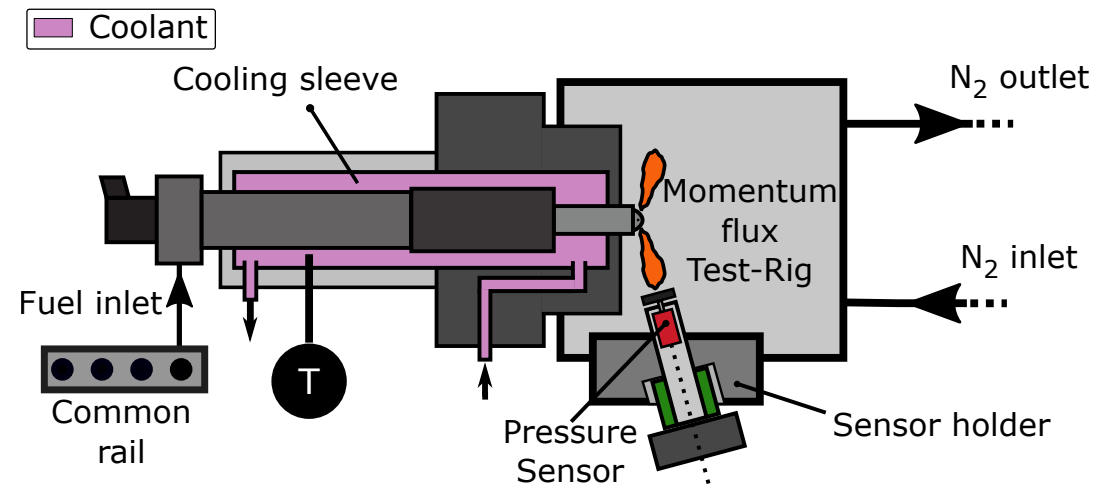

Figure 2. Momentum Flux Test Rig diagram.

\section{$\mathrm{OH}^{\star}$ chemiluminescence measurements}

$\mathrm{OH}^{*}$ chemiluminescence measurements were done in a high-pressure and high-temperature test rig, with an optically accessible combustion chamber with constant-pressure flow. The test rig can simulate the boundary conditions found in the combustion chamber of compression ignition engines, reaching temperatures and pressures up to $1100 \mathrm{~K}$ and $15 \mathrm{MPa}$, respectively. This test rig is thoughtfully detailed in [9].

The optical setup employed to capture $\mathrm{OH}^{*}$ chemiluminescence is depicted in Figure 3. First, the light goes through the narrow band-pass filter of $310 \pm 5 \mathrm{~nm}$ placed in front of the camera. Thus, only the desired emittance goes through, a methodology frequently employed to capture $\mathrm{OH}^{*}$ chemiluminescence $[10,11]$. Then, the filtered light goes through the Hamamatsu $\mathrm{C} 10880$ image intensifier coupled to the Photron FastCam SA5, in which the images are recorded.

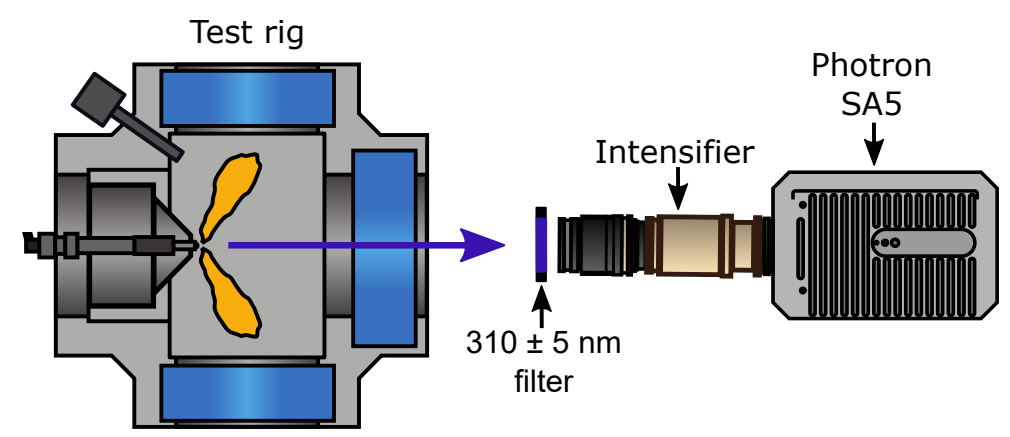

Figure 3. $\mathrm{OH}^{\star}$ chemiluminescence optical setup.

The images were captured at an image resolution of $736 \times 320$ pixels, where 4.39 pixels equals one millimeter. Additionally, the images were obtained at a frequency of $25 \mathrm{kfps}$. An example of the time-dependent lift-off length recorded through this setup is presented on Figure 4. Then, the lift-off length of the stabilized spray was calculated following the Engine Combustion Network guidelines, a methodology explained in detail in [12].

\section{Test Matrix}

The Boundary conditions employed throughout the experiments are depicted in Table 2 and Table 3.

The repetitions of each test point were averaged into a final value, and the shot-to-shot dispersion is evaluated through the relative standard deviation (RSD), which was below $5 \%$ for every condition tested.

\section{Results and discussion}

The following section details the phenomena observed throughout the measurements. First, momentum flux results are described to observe the hydraulic behavior of each spray. Then, 

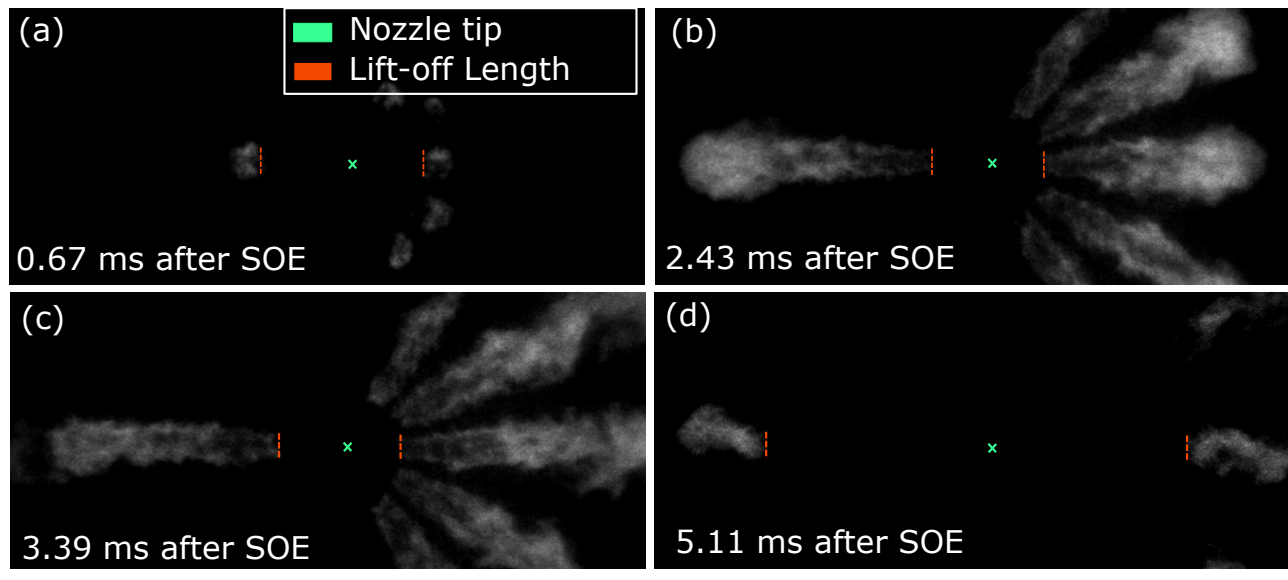

Figure 4. $\mathrm{OH}^{*}$ chemiluminescence sequence after start of injection.

Table 2. Test plan for the momentum flux campaign.

\begin{tabular}{lcc}
\hline Parameter & Value & Units \\
\hline Injection pressure & $100-150-200$ & $\mathrm{MPa}$ \\
Back pressure & $2-5-8$ & $\mathrm{MPa}$ \\
Ambient gas & Nitrogen & - \\
Injection frequency & 1 & $\mathrm{~Hz}$ \\
Cycles per test point & 50 & - \\
\hline
\end{tabular}

Table 3. Test plan for the $\mathrm{OH}^{\star}$ Chemiluminescence Campaign.

\begin{tabular}{lcc}
\hline Parameter & Value & Units \\
\hline Injection pressure & $100-150-200$ & $\mathrm{MPa}$ \\
Chamber Temperature & $800-900-1000$ & $\mathrm{~K}$ \\
Chamber density & $15.2-22.8-30.4$ & $\mathrm{~kg} / \mathrm{m}^{3}$ \\
Ambient gas & Ambient Air & - \\
Injection frequency & 0.25 & $\mathrm{~Hz}$ \\
Energizing time & 1.5 & $\mathrm{~ms}$ \\
Cycles per test point & 10 & - \\
\hline
\end{tabular}

$\mathrm{OH}^{*}$ chemiluminescence results are presented, analyzing the change in behavior of the lift-off length due to inter-jet spacing variations.

\section{Momentum flux}

Figure 5 depicts momentum flux curves for each hole of interest. It can be seen that, for the same electric pulse, the hydraulic response of all the holes is similar, as the injection starts and ends at the same time. Moreover, the momentum flux stabilizes around the same values, indicating a similar amount of mass injected, as both parameters are closely related [7].

The similarity depicted in Figure 5 is representative of the behavior observed throughout the entire momentum flux measurements, as represented in Figure 6, which depicts the momentum coefficient of every condition tested, computed by the equation Equation 1 [8]:

$$
C_{M}=\frac{\dot{M}}{\dot{M}_{\text {theor }}}=\frac{\dot{M}}{2 A_{o} \Delta P}
$$

Where $\dot{M}$ represents the stable Momentum flux value, $A_{o}$ the theoretical outlet area of the orifice and $\Delta P$ the difference between the injection pressure and the back pressure.

Moreover, the dashed line represents the mean momentum coefficient of each hole, with its value specified on the bottom-right corner of the Figure 6 . Thus, a high similarity in hydraulic behavior between holes is observed in terms of momentum flux measurements. 

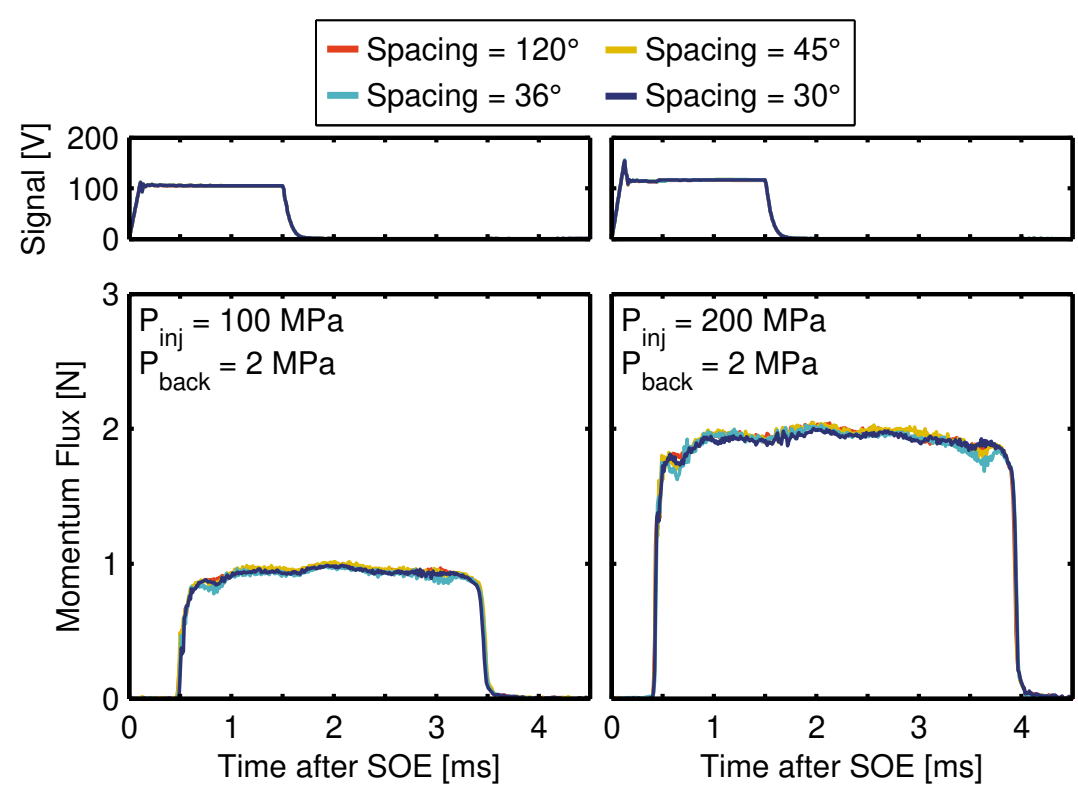

Figure 5. Momentum Flux signal for each orifice.

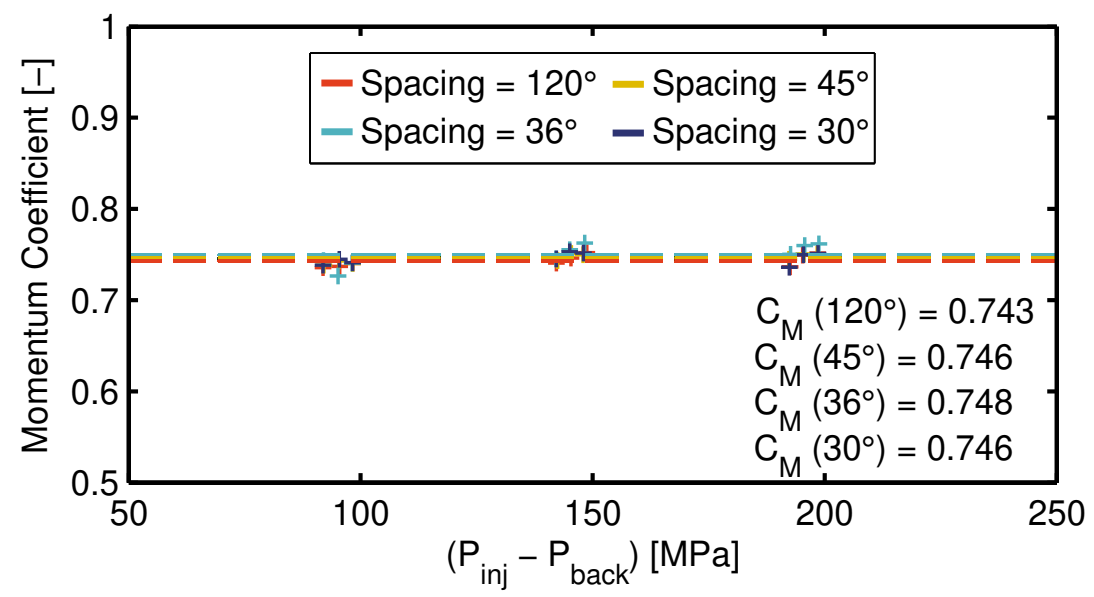

Figure 6. Momentum Flux coefficient for each orifice.

\section{Lift-off length}

This section contains a detailed analysis of the lift-off length values obtained throughout the experiments. To improve the readability of the figures, the results of each injector are plotted separately.

In this sense, Figure 7 and Figure 8 depict lift-off length for several boundary conditions. It can be seen that the lift-off length decreases as the chamber temperature or density increases. Moreover, a larger lift-off length is observed when the injection pressure increases. These phenomena have been observed in previous studies [10,13,14], and serve to validate the consistency of the results obtained in this work.

On the other hand, considerable lift-off length variations were found between the different jetto-jet spacing configurations. Specifically, a reduction of the lift-off length was noted for closely spaced jets. For instance, the spray with an inter-jet spacing of $30^{\circ}$ had considerably lower lift-off length values than the isolated spray (represented as the spray with $120^{\circ}$ of spacing) for every condition tested, as depicted in the right-plot of Figure 7 and Figure 8 . This trend was also found in the injector $3 \mathrm{v} 3$, although smaller differences were observed between the sprays of study, in line with the more similar inter-jet spacing values.

This change in behavior was found throughout every boundary point, as depicted in Figure 9. This figure illustrates the relative lift-off length for every condition tested, a normalized value 


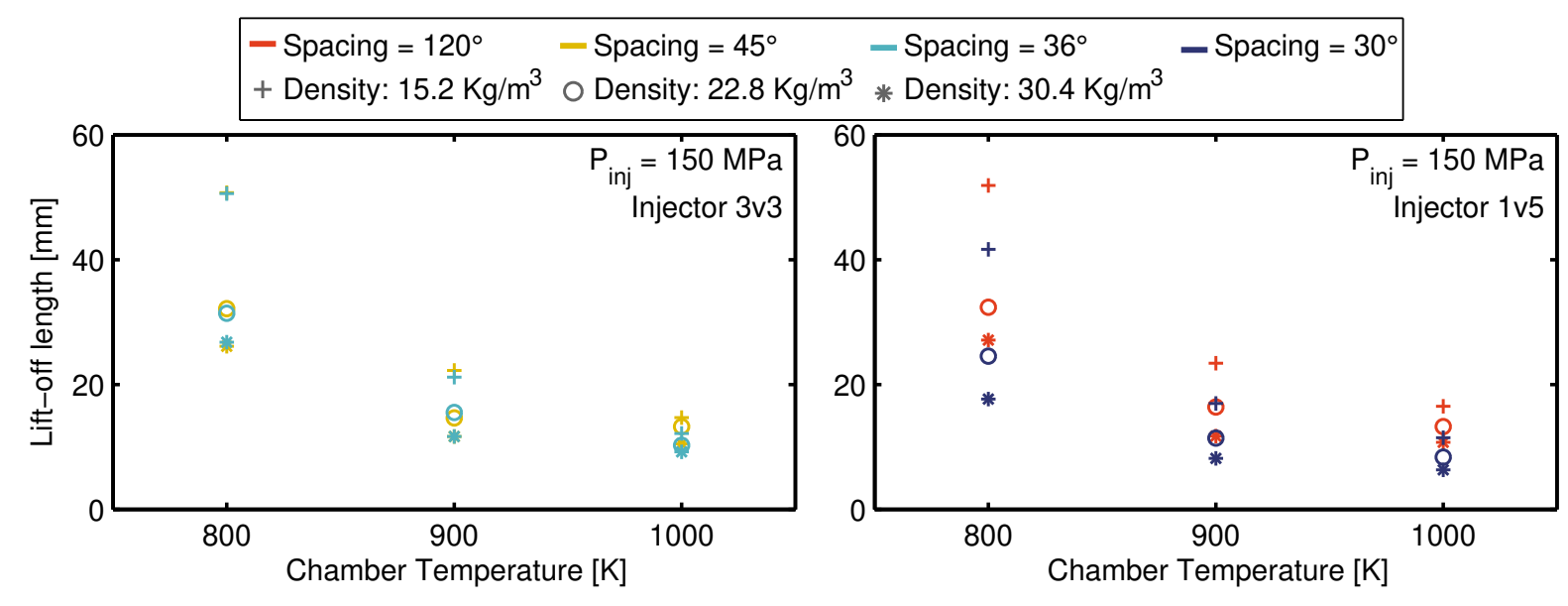

Figure 7. Lift-off length variation for several values of inter-jet spacing, chamber density, and chamber temperature.

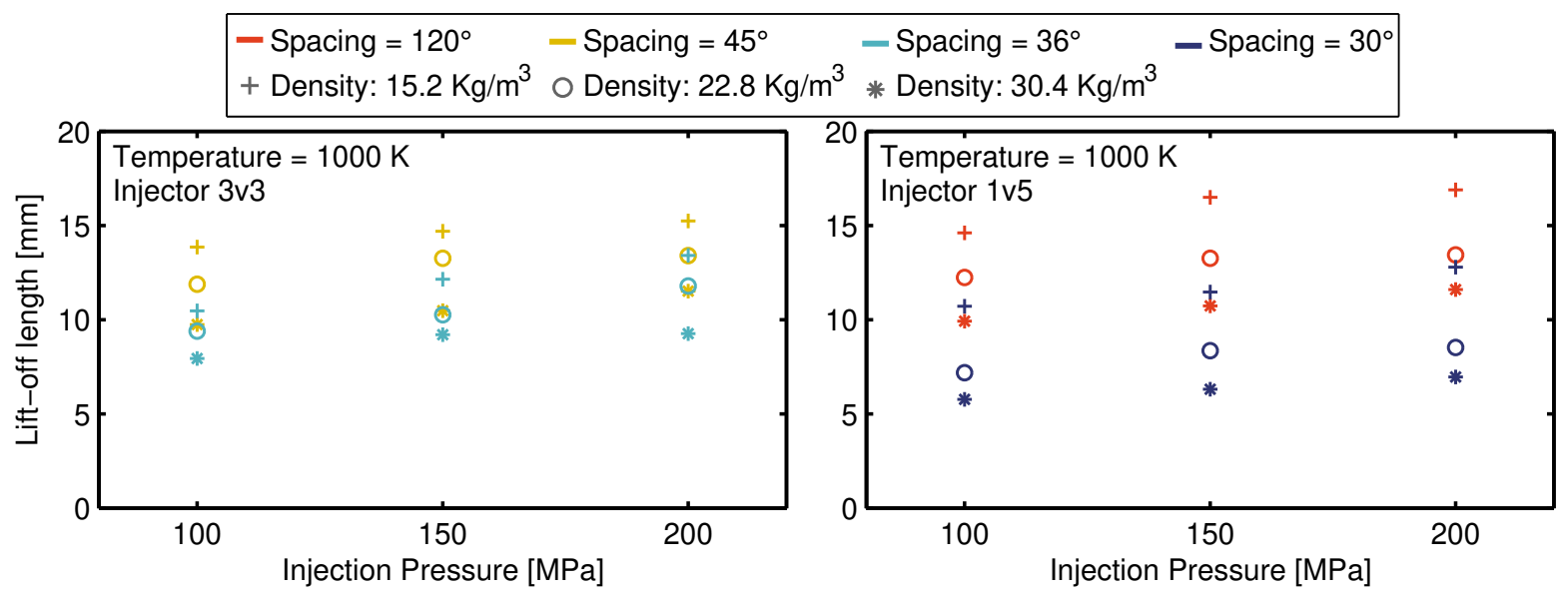

Figure 8. Lift-off length variation for several values of inter-jet spacing, chamber density, and injection pressure.

computed to assess the influence of inter-jet spacing more clearly. To do so, each lift-off length value was divided by the lift-off length obtained with the isolated spray (spacing $=120^{\circ}$ ) at the same boundary condition, obtaining the relative Lift-off length.

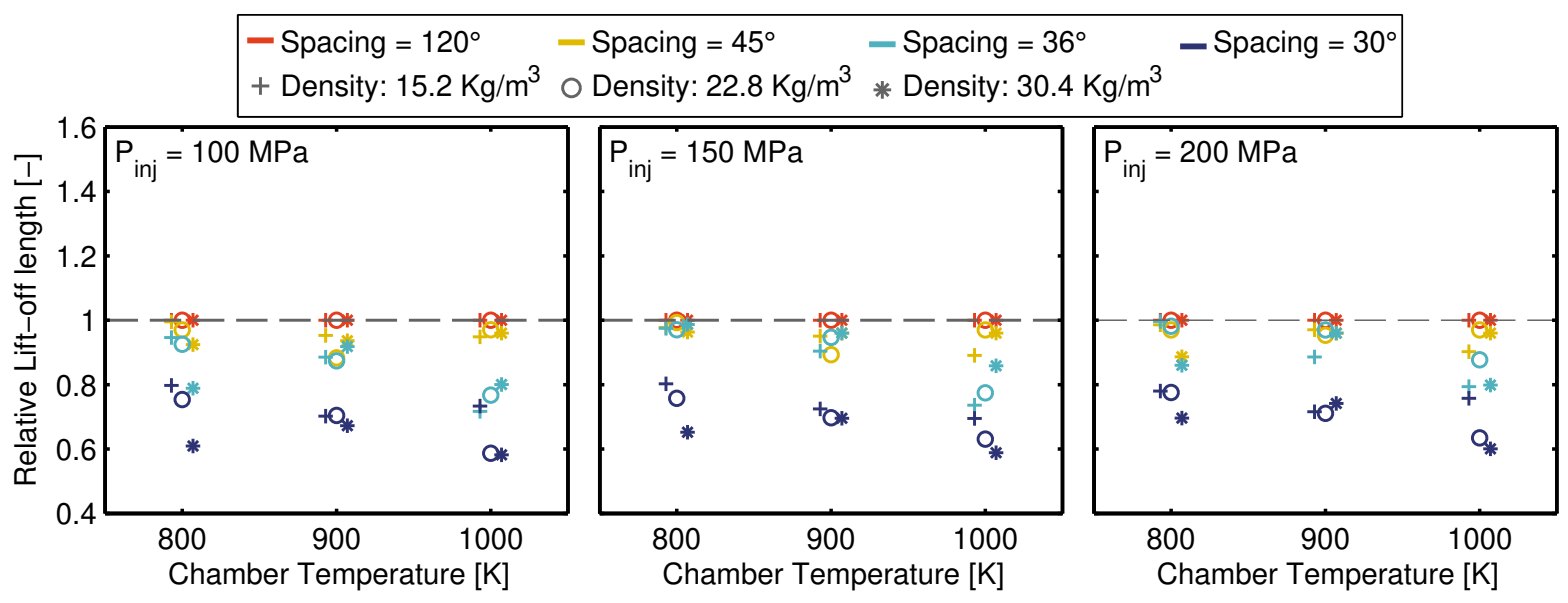

Figure 9. Lift-off length variation for several values of inter-jet spacing.

It is detailed with more clarity that the spray with $30^{\circ}$ of spacing had lower lift-off length values than any of the other inter-jet spacing configurations for every condition tested. Moreover, the spray with $36^{\circ}$ of inter-jet spacing tended to have a slightly smaller lift-off length value than the 
spray with $45^{\circ}$ of spacing, which had lift-off length values closer to those of the isolated spray. Lastly, the results show that the changes in behavior were generally larger as the chamber density and temperature increased.

In this sense, the results showed that after certain proximity between sprays is reached, the interaction between them becomes a relevant factor, and the lift-off length is considerably reduced, in unity with the observations noted in [15].

A possible cause of the observed changes in behavior is the reduction of inter-jet spacing, as this physical change would reduce the space available to entrain fresh air. In consequence, this could cause an increase in the proportion of entrained hot combustion products and radicals that appear along the periphery of the spray [16]. Then, the entrained gas with higher temperature could promote auto-ignition near the nozzle, consequently reducing the lift-off length, as seen in $[16,17]$.

\section{Conclusions}

In this work, the influence of inter-jet spacing on lift-off length has been studied. To do so, the behavior of the isolated spray was compared to the spray development under three inter-jet spacing configurations: $30^{\circ}, 36^{\circ}$ and $45^{\circ}$. From the results obtained, the following conclusions are drawn:

- After certain proximity between sprays is reached, the lift-off length is considerably reduced as the interaction between sprays becomes a relevant factor. In particular, the spray with $30^{\circ}$ of spacing had lower lift-off length values than any other inter-jet spacing configuration for every condition tested.

- The momentum flux measurements revealed a high resemblance in hydraulic behavior between the sprays, discarding this as a possible cause of the observed changes in behavior.

- A plausible cause of the observed changes in behavior is an increment of the entrained hot combustion products located along the periphery of the spray. Specifically, the entrained gas with higher temperature could induce autoignition around the nozzle region, causing a retraction of the lift-off length.

- A reduction of the lift-off length was also observed as the chamber temperature or density increased. Moreover, a larger lift-off length was noted when the injection pressure increased. This is a well-known spray behavior and serves to validate the consistency of the results obtained in this work.

\section{Acknowledgements}

This work has been partially funded by Spanish Ministerio de Ciencia, Innovación y Universidades, through project RTI2018-099706-B-100. Tomas Montiel was supported by a research grant from Generalitat Valenciana and the European Social Fund (Reference: ACIF/2018/122).

\section{Nomenclature}

$A_{o} \quad$ Theoretical outlet area

$C_{M} \quad$ Momentum flux Coefficient

$L O L \quad$ Lift-off length

$\dot{M} \quad$ Stable momentum flux

$\Delta P \quad P_{i n j}-P_{b a c k}$
$P_{\text {back }} \quad$ Back pressure

$P_{i n j} \quad$ Injection Pressure

$R S D$ Relative Standard Deviation

$S O E \quad$ Start of Energizing 


\section{References}

[1] Johnson, T., 2016, "Vehicular Emissions in Review," SAE International Journal of Engines, 9(2), pp. 1258-1275.

[2] Lahane, S. and Subramanian, K. A., 2014, "Impact of nozzle holes configuration on fuel spray, wall impingement and NOx emission of a diesel engine for biodiesel-diesel blend (B20)," Applied Thermal Engineering, 64(1-2), pp. 307-314.

[3] Han, S., Kim, J., and Bae, C., 2014, "Effect of air-fuel mixing quality on characteristics of conventional and low temperature diesel combustion," Applied Energy, 119, pp. 454-466.

[4] Aori, G., Hung, D. L. S., and Zhang, M., 2016, "Effect of Nozzle Configuration on Macroscopic Spray Characteristics of Multi-Hole Fuel Injectors Under Superheated Conditions," Atomization and Sprays, 26(5), pp. 439-462.

[5] Rusly, A. M., Le, M. K., Kook, S., and Hawkes, E. R., 2014, "The shortening of lift-off length associated with jet-wall and jet-jet interaction in a small-bore optical diesel engine," Fuel, 125, pp. 1-14.

[6] Chartier, C., Aronsson, U., Andersson, Ö., Egnell, R., and Johansson, B., 2013, "Influence of jet-jet interactions on the lift-off length in an optical heavy-duty di diesel engine," Fuel, 112, pp. 311-318.

[7] Payri, R., Gimeno, J., Martı-Aldaravi, P., and Viera, A., 2020, "Measurements of the mass allocation for multiple injection strategies using the rate of injection and momentum flux signals," International Journal of Engine Research.

[8] Payri, R., Martí-Aldavarí, P., Montiel, T., and Viera, A., 2020, "Influence of aging of a diesel injector on multiple injection strategies," Applied Thermal Engineering, 181(August), p. 115891.

[9] Payri, R., Gimeno, J., Cardona, S., and Ayyapureddi, S., 2019, "Experimental study of the influence of the fuel and boundary conditions over the soot formation in multi-hole diesel injectors using high-speed color diffused back-illumination technique," Applied Thermal Engineering, 158, p. 113746.

[10] Benajes, J., Payri, R., Bardi, M., and Martí-aldaraví, P., 2013, "Experimental characterization of diesel ignition and lift-off length using a single-hole ECN injector," Applied Thermal Engineering, 58(1-2), pp. 554-563.

[11] Bardi, M., Payri, R., Malbec, L.-M., Bruneaux, G., Pickett, L. M., Manin, J., Bazyn, T., and Genzale, C. L., 2012, "Engine Combustion Network: Comparison of Spray Development, Vaporization, and Combustion in Different Combustion Vessels," Atomization and Sprays, 22(10), pp. 807-842.

[12] Pastor, J. V., García, A., Micó, C., and García-Carrero, A. A., 2020, "Experimental study of influence of Liquefied Petroleum Gas addition in Hydrotreated Vegetable Oil fuel on ignition delay, flame lift off length and soot emission under diesel-like conditions," Fuel, 260(July 2019), p. 116377.

[13] Higgins, B. and Siebers, D. L., 2001, "Measurement of the Flame Lift-Off Location on DI Diesel Sprays Using OH Chemiluminescence," SAE Technical Paper 2001-01-0918.

[14] Lequien, G., Li, Z., Andersson, O., and Richter, M., 2015, "Lift-Off Length in an Optical Heavy-Duty Diesel Engine," SAE International Journal of Engines, 8(5), pp. 2015-242442.

[15] Bazyn, T. and Koci, C., 2014, "The Effect of Jet Spacing on the Combustion Characteristics of Diesel Sprays," THIESEL 2014 Conference on Thermo- and Fluid Dynamic Processes in Direct Injection Engines, pp. 1-19.

[16] Pickett, L. M., Kook, S., Persson, H., and Andersson, Ö., 2009, "Diesel fuel jet lift-off stabilization in the presence of laser-induced plasma ignition," Proceedings of the Combustion Institute, 32, pp. 2793-2800.

[17] Persson, H., Andersson, Ö., and Egnell, R., 2011, "Fuel effects on flame lift-off under diesel conditions," Combustion and Flame, 158(1), pp. 91-97. 